\title{
PUBLIC EXPECTATION AS AN ELEMENT OF HUMAN PERCEPTION OF CLIMATE CHANGE
}

\author{
MARTINE REBETEZ \\ Department of Geography of the Universities of Lausanne and Fribourg, Switzerland ${ }^{*}$
}

\begin{abstract}
Human expectations regarding weather and climate sometimes lead to perceptions of climate change which are not supported by observational evidence. This paper analyses two very characteristic complaints about current climate in Switzerland, i.e., the lack of snow in winter and the lack of sunshine in summer, through a statistical investigation of climatological data. As one major problem of public perception of climate in mid-latitude regions is linked to the strong variability of the climatic parameters, the paper suggests means of presenting climatic data which include a measure of this variability. Such presentations would help overcome the common confusion between the terms 'weather' and 'climate', and stress the fact that short-term extreme events are not necessarily indicative of a long-term shift in climate.
\end{abstract}

\section{Introduction}

Human dimensions of global climate change is becoming an increasingly important issue (Jaeger et al., 1993; Stern et al., 1992; Jacobson et al., 1990) and in this context the transfer of scientific information on climate to the general public poses problems for a number of reasons (Kearney, 1994), in particular:

- the direct perception of climate change by humans is practically impossible because of the temporal scales associated with this change;

- the vast spatial scales characteristic of global change are difficult to relate to everyday life (compared for instance to direct effects of air or water pollution);

- global change issues are often too abstract and cannot be related to personal experience.

People tend to confuse stratospheric ozone depletion with the greenhouse effect and weather with climate (Bostrom et al., 1994). Pielke (1994) highlighted the difficulties of transferring scientific information concerning global environmental change from scientists to the US Congress, illustrating how difficult it is for policymakers to receive and make use of information for decision-making purposes. Even well-educated non-specialists make important confusions with the key issues concerning climate change (Read et al., 1994; Kempton et al., 1995). Lay people, the media, politicians and even scientists from other disciplines react to climatechange issues mainly on the basis of their own everyday experience, when they feel that they themselves have been subjected to tangible signs of climate change.

* Address: BFSH2, Dorigny, CH-1015 Lausanne, Switzerland. 
Effective transfer of scientific information can only be achieved if scientists are conscious of certain biases in the public's conceptions of climate and if they take the public's expectations into consideration. This paper describes the issues underlying some of these expectations and suggests means of presenting climatic data in such a manner that expectations do not distort the information and make it ineffective, and so that the confusion highlighted by Bostrom et al. (1994) between 'weather' and 'climate' can be reduced. In order to develop these topics, the specific example of Switzerland, well endowed with climatological data, has been chosen.

Ways of life have changed dramatically during the 20th century. Switzerland, which has never had any big industrial complexes as in other places in Europe or in the United States, was transformed from a mainly agricultural society (95\% of employments in agriculture in 1901) into one with a majority of employments in the tertiary sector (64\% of employments in 1990 compared to only $4 \%$ in agriculture) (OFS, 1992). Socio-economic impacts of climate change can be expected to be very different now from what they were 100 or 50 years ago (Jacobsen and Price, 1990). For example, during a succession of winters between 1988 and 1991, the lack of snow and persistent sunshine in the Alps were the source of significant economic adversity in the tourist industry (Abegg et al., 1994). In this context, the transfer of information concerning not only climatic change but climate in general is particularly important.

\section{The Example of the Expectation of White Christmases}

In Switzerland, Christmas is occasionally 'White' and the presence of a White Christmas depends essentially on altitude. Most people are nevertheless convinced that White Christmases have become less and less frequent during the 20th century and even in the last 20 or 30 years. This is a widely shared idea in Switzerland, although no fundamental study of this perception has been undertaken.

An analysis of snow data (snow depth at $7 \mathrm{am}$ ) from the Swiss Climate Data Base (SCDB) shows the frequencies of the presence of snow cover on December 25 on the basis of two different snow depth thresholds, i.e., 1 and $10 \mathrm{~cm}$, respectively. Though one centimeter of snow does not correspond to the traditional Christmas illustrations and greeting cards, even a very small amount of snow may transform a scenery sufficiently for it to be called White Christmas. With $10 \mathrm{~cm}$ or more, the snow cover begins to correspond to the Christmas iconography.

Figure 1 shows the frequencies of snow cover on December 25 at 22 meteorological stations distributed at different altitudes in Switzerland. These include the Swiss Plateau, the Jura mountains and the Alps (excluding the southern side of the Alps which experiences a milder, Mediterranean type climate in winter). The stations are located on the map given in Figure 2. In most cases, snow has been measured each day since 1931 and the latest data used here are for 1993. 


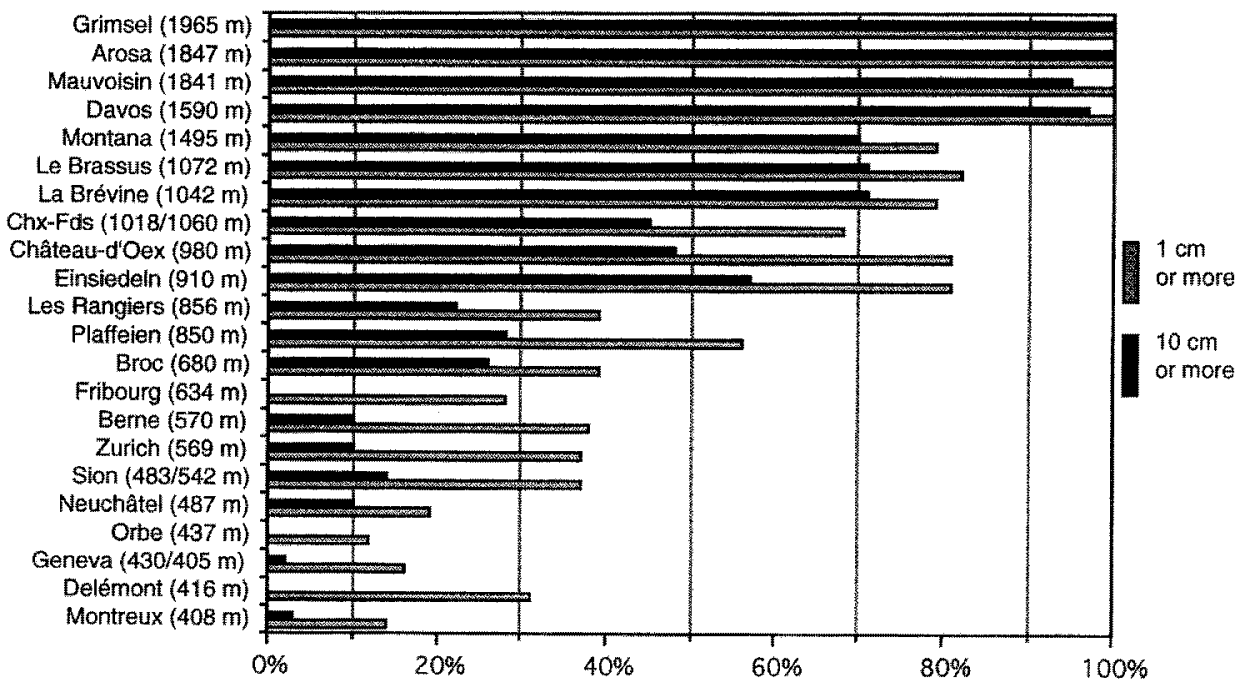

Figure 1. Frequencies of the occurrence of snow on Christmas morning ( $7 \mathrm{am}$ ) for several Swiss locations.

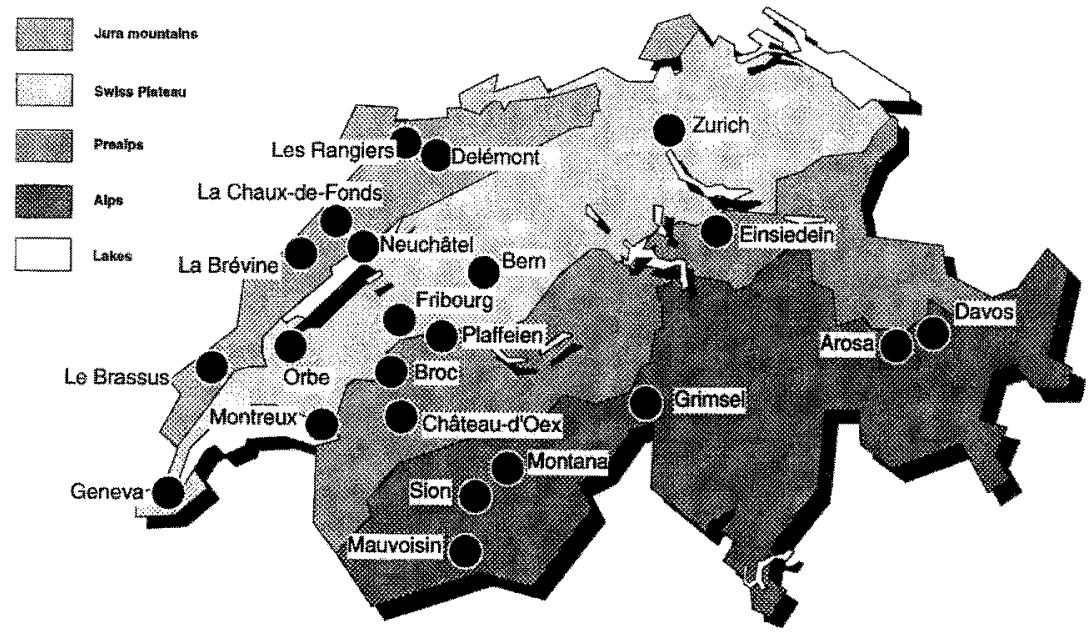

Figure 2. Locations of the observing sites (Swiss climate database).

As far as the $1 \mathrm{~cm}$ threshold is concerned, Figure 1 shows that at least 2 Christmases out of 3 were not 'White' below $700 \mathrm{~m}$; there was snow only one year out of 5 on the Swiss Plateau below $500 \mathrm{~m}$, which is where most of the Swiss population resides (65\% below $500 \mathrm{~m}, 90 \%$ below $700 \mathrm{~m}$; OFS, 1992). The $10 \mathrm{~cm}$ threshold is reached only one year out of two in the altitude range $900-1000 \mathrm{~m}$ and higher. Christmases without snow are exceptional above about $1500 \mathrm{~m}$. In the mountains, White Christmases represent the most frequent case whereas Christmases without snow are generally the rule in the plains. 
Trend analyses for these data show that there is no long-term tendency either in the absolute value of snow depth recorded each Christmas, or in the frequency of occurrence of snow on this date, whatever the threshold (Figure 3). This is in close agreement with recent analyses of snow depth in mountains (Barry, 1995; Beniston et al., 1994). On the other hand the figure shows clearly the strong interannual variability of snow cover both in terms of its presence or absence, and its depth; this implies that any perception of long-term change in snow, especially concerning only one particular day in the year (i.e., Christmas Day), is almost impossible. In Neuchâtel, snow at Christmas is such a rare phenomenon that statistical representations such as arithmetical means and long-term tendencies are inadequate. A long series of 'White' or 'Green' Christmases cannot in itself be considered exceptional, nor is it necessarily an indicator of a long-term tendency.

Nevertheless, these data do not exclude the possibility that a significant change may have occurred before the 20th century, a period for which computerized data do not exist in Switzerland. H. H. Lamb (1988) has analysed historical data from London, existing since 1650; these data exhibit no significant long-term tendency. The period of the Little Maunder Minimum, which brought noticeably cold temperatures to England and Western Europe (Wanner et al., 1994) does not appear to exhibit significant differences in the number of White Christmases, due either to snow or to frost. This period was in fact characterized not only by low temperatures but also by a relative absence of precipitation.

\subsection{HYPOTHESES TO EXPLAIN THE ORIGINS OF THE WHITE CHRISTMAS IMAGE}

This dichotomy between a preconceived idea and the history of climate is not very surprising as it has been shown that human perception of long-term tendencies is extremely limited, compared to the perception of short-lived extreme events (White, 1985; Farhar-Pilgrim, 1985). White has shown that humans are mainly able to perceive natural catastrophies and very abnormal weather situations. Significant climatic differences from one year or one season to the next are more readily perceived than variability on a decadal scale. The Metromex experiment (Farhar-Pilgrim, 1985) has shown that a $30 \%$ increase in precipitation over 30 years could go by unnoticed, although farmers had actually observed an increase in the crop's return during this period; however, they generally attributed this result to improvements in agricultural techniques.

We can nevertheless attempt to put forward some hypotheses to explain the origin of the notion that snow at Christmas is decreasing. The first Christmas greeting card is believed to have been printed in London as late as 1843 (Hornung, 1970). It does not show any particular landscape but depicts a festive atmosphere: people are drinking and there are many decorations, mainly in the form of grapes around the group. This illustration evokes autumn rather than winter and does not appear to be related to any particular season; the main point conveyed by this image is the myrth and light atmosphere. In 1845, another greeting card (ibid.) 

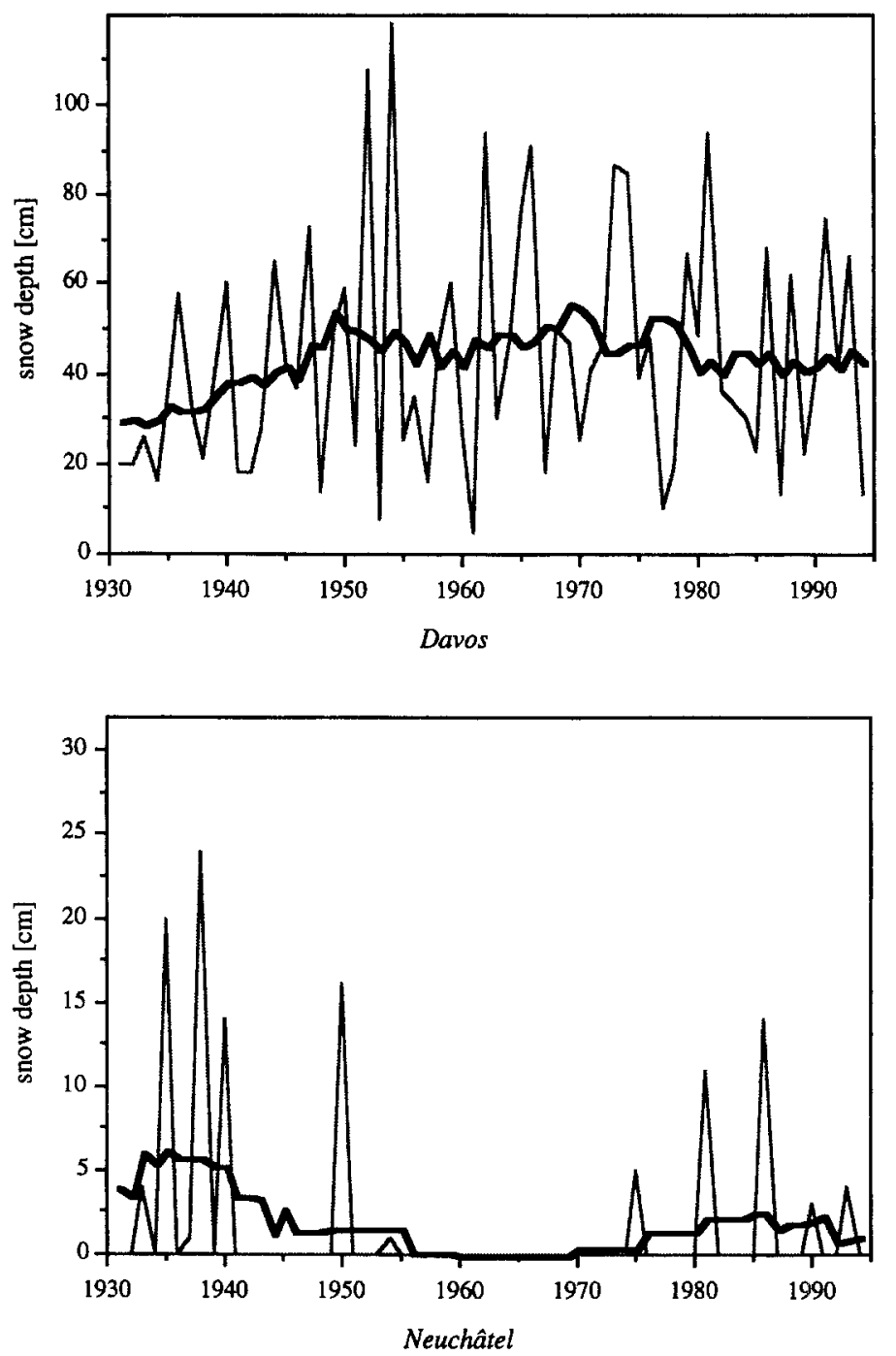

Figure 3. Snow depth on Christmas morning from 1931 to 1994 in Davos (1590 m and Neuchâtel $(487 \mathrm{~m})$.

shows Father Christmas standing next to a chimney with the rooftops of the town around him (Figure 4). It is obvious that these rooftops as well as the chimney which Father Christmas is about to enter are all free of snow. In 1863, on the contrary, the same kind of illustration (Figure 5) shows large amounts of snow.

A study of Christmas customs through numerous illustrated books does not reveal any illustration depicting snow prior to 1850 . The first illustrations with snow appear between 1850 and 1860, a period during which they are still the exception, but they soon become the rule thereafter. This modification of the image 


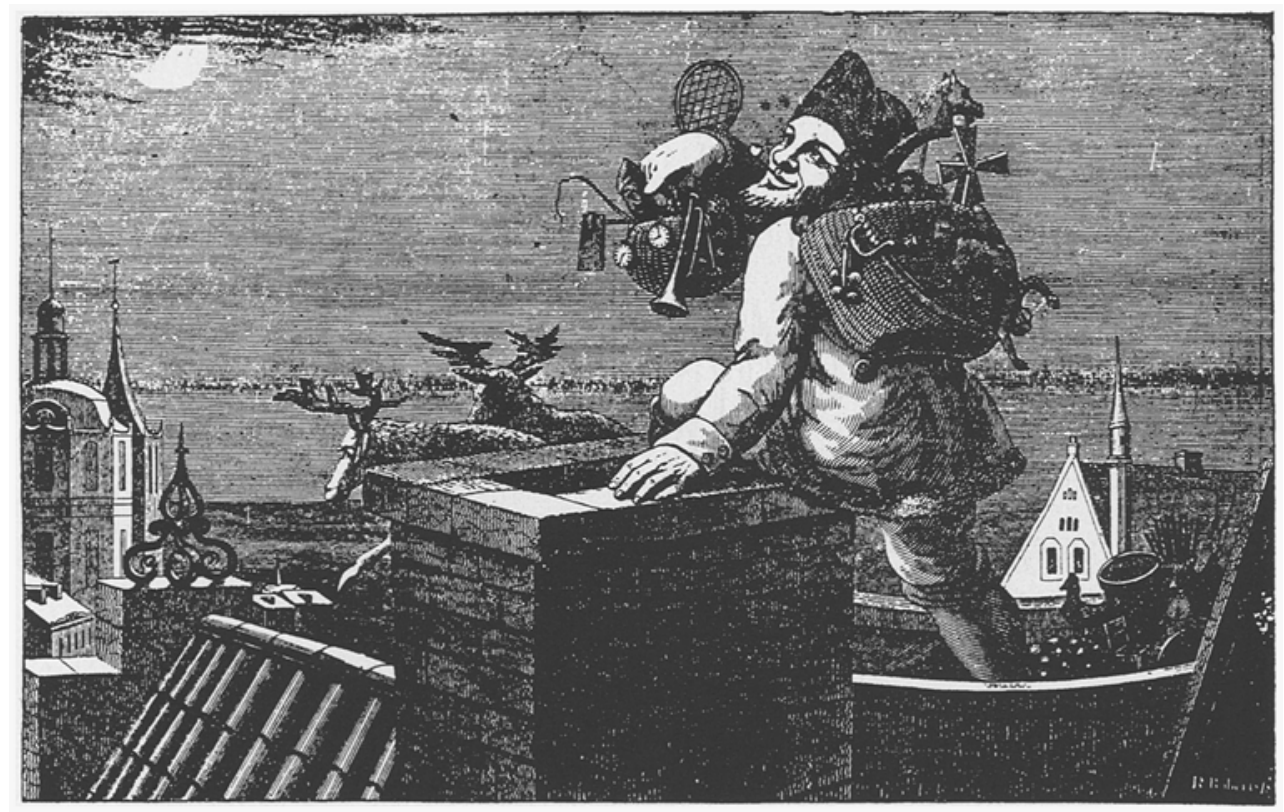

Figure 4. Father Christmas in 1845. The rooftops are clearly free of snow. (From Hornung, 1970, this illustration is not subject to any permission for reproduction).

of Christmas is likely to be related to a fashion phenomenon which may have originated either in the discovery, mainly by the British, of the Alps in winter, or to an influence of New England in the United States, where snow is often abundant at Christmas, or to a combination of both these factors. This image has spread all over the world, generally for reasons of fashion and aesthetics. White Christmas greeting cards are sent not only in New York, London or Geneva, but also in Houston, Singapore or Sydney, in the middle of the Southern Hemisphere summer. The particularity of a place such as the Swiss Plateau, compared to Houston or Sydney is that, although snow is not the dominant feature of the Christmas period, it is present from time to time, and it can usually be seen on the nearby mountains. If it is obvious that in Sydney, the very idea of snow at Christmas is linked to other places in the world, people in Switzerland could easily believe that this image corresponds to a foregone reality.

Although this hypothesis cannot be proved, a corroboration of the interpretation that expectations of a white Christmas are a recent phenomenon comes from Swiss traditional sayings, which originated before and up to the 19th century. Among these, none brings up an expectation of snow at Christmas (Rebetez, 1994). For the plains, certain sayings related to snow cover do exist for the months of January and February, as snow, at this season has a positive impact on agriculture (i.e., by insulating the soil from damaging frosts). As far as Christmas is concerned, sayings mentioning snow confirm that it may be present or absent, with a common belief 


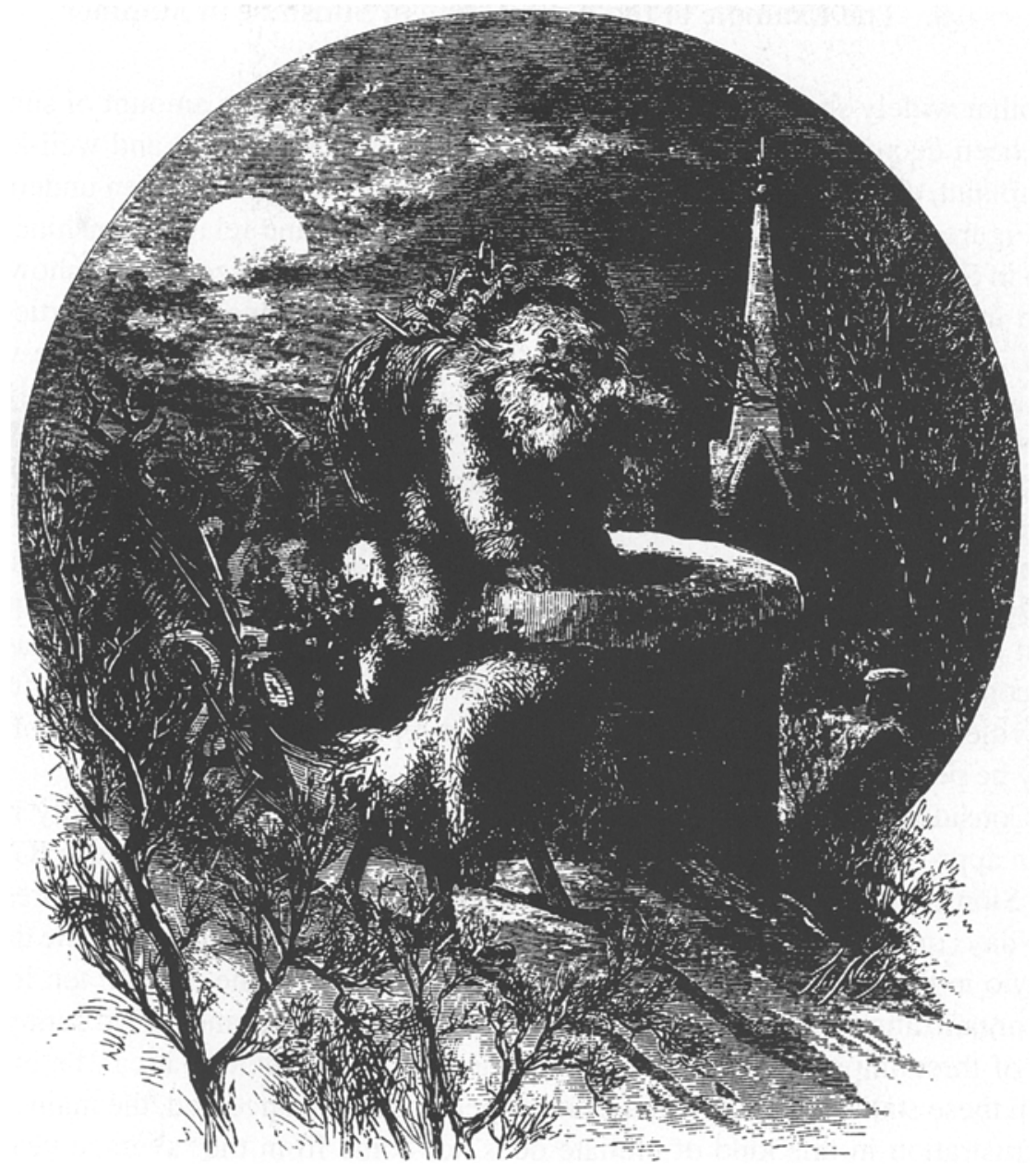

Figure 5. Father Christmas in 1863. Snow is a dominant figure of this illustration. (From Hornung, 1970 , this illustration is not subject to any permission for reproduction).

that the absence of snow at Christmas will be 'compensated' for by snow or cold weather at Easter, and vice versa (Rebetez, 1986).

As climate change is generally impossible for humans to perceive on this scale and although climate changes have taken place throughout time in the Alps in the last centuries (Bradley and Jones, 1992), the principal hypothesis to explain present-day expectations of snow at Christmas is linked to a phenomenon of fashion and aesthetics. 


\section{The Example of the Expectation of Sunshine in Summer}

Another widely shared idea in Switzerland is the fact that the amount of sunshine has been decreasing in recent years or decades. It is a common and well-known complaint, although no fundamental study of this perception has been undertaken.

Figure 6 presents the average evolution of absolute and relative sunshine duration in Switzerland, on the basis of daily records for the 20th century. It shows that both in the mountains and in the Swiss Plateau, the summer period, particularly July, corresponds to the sunniest period of the year, not only in absolute values but also in relative values. Nevertheless, if sunshine is more frequent in July than in May or December, its presence is never an absolute certainty. Although July has the highest probability of sunshine, the frequency of occurrence rarely exceeds $60 \%$. In order to provide a more detailed representation of sunshine data as close as possible to the human perception of sunshine duration, an analysis has been made of the number of sunny days in July. These are defined as the number of days with at least $70 \%$ or $50 \%$ of potential duration. The $70 \%$ threshold can usually be considered as quantifying a truly sunny day, in the sense that most outdoor activities can take place. The 50\% threshold represents the lowest limit of what may be perceived as a sunny day.

Considering the $70 \%$ threshold, the frequency of occurrence for July ranges from approximately one day in two at the sunniest climatological stations (Geneva and Sion), to less than one day in three in the Jura mountains. For the 50\% threshold, two days out of three are sunny in Geneva and in the Rhône Valley and one day out of two in the Jura mountains. A 50\% probability of sunshine is often too low for the organization of outdoor activities such as hiking for instance. Two sunny days out of three improves the situation considerably. Nevertheless, it can be inferred from these statistics that, as far as human perception is concerned, the main source of frustration in this kind of climate does not come from the 'average year' but from the years which appear to differ from the average.

Figure 7 illustrates the interannual variability in the number of sunny days. This example shows that in Geneva, for an average of 15.8 sunny days at the $70 \%$ relative sunshine duration threshold, July statistics range this century from 6 to 26 sunny days. Even with the 50\% threshold, there may be only 11,12 or 13 sunny days in July in Geneva. Such frequencies can easily be reached in other months of the year; although it may not be particularly abnormal in a long-term perspective, low frequency of sunshine duration in July constitutes a notable anomaly in the year concerned, as this month is no longer the sunniest one of the year. This is in agreement with the results obtained by Berk et al. (1995) who have shown that climate variability poses an important problem for the public's perception of climate.

The interannual variability is as high for the $50 \%$ threshold as for the $70 \%$ one, although the extreme years are not necessarily the same in both cases. It can thus be assumed here that this strong interannual variability in the sunshine duration 

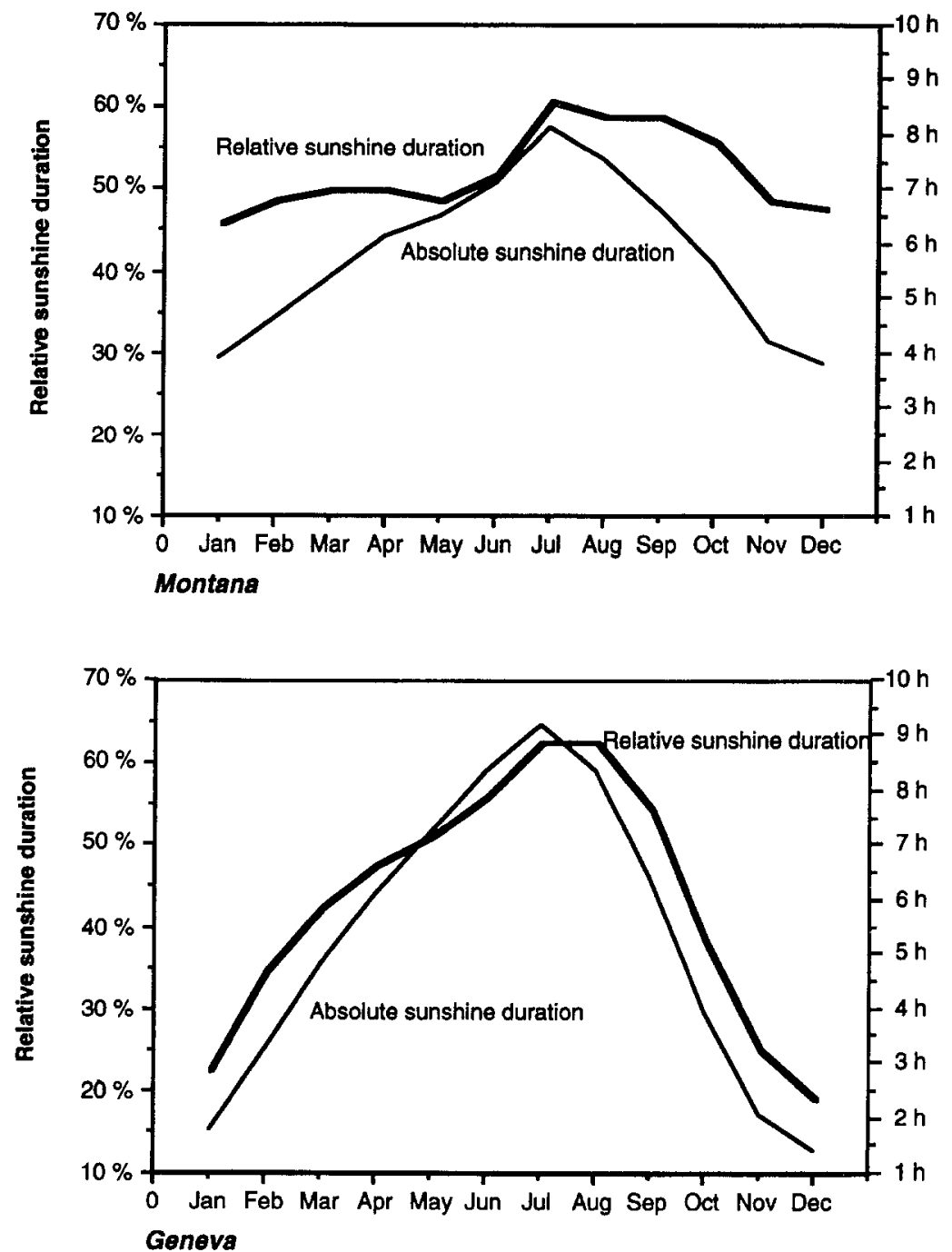

Figure 6. Monthly means of relative and absolute sunshine duration at low elevations (Geneva, 405/430 m, 1901-1993) and in an alpine meteorological station (Montana, $1495 \mathrm{~m}, 1931-1993$ ).

explains most of the frustration related to the expectation of sunny weather in summer. This expectation may be justified on the average, but differences may be so high from one year to the next that it is not exceptional for July to exhibit less relative sunshine than other months of the same year, including in some instances December or January. 


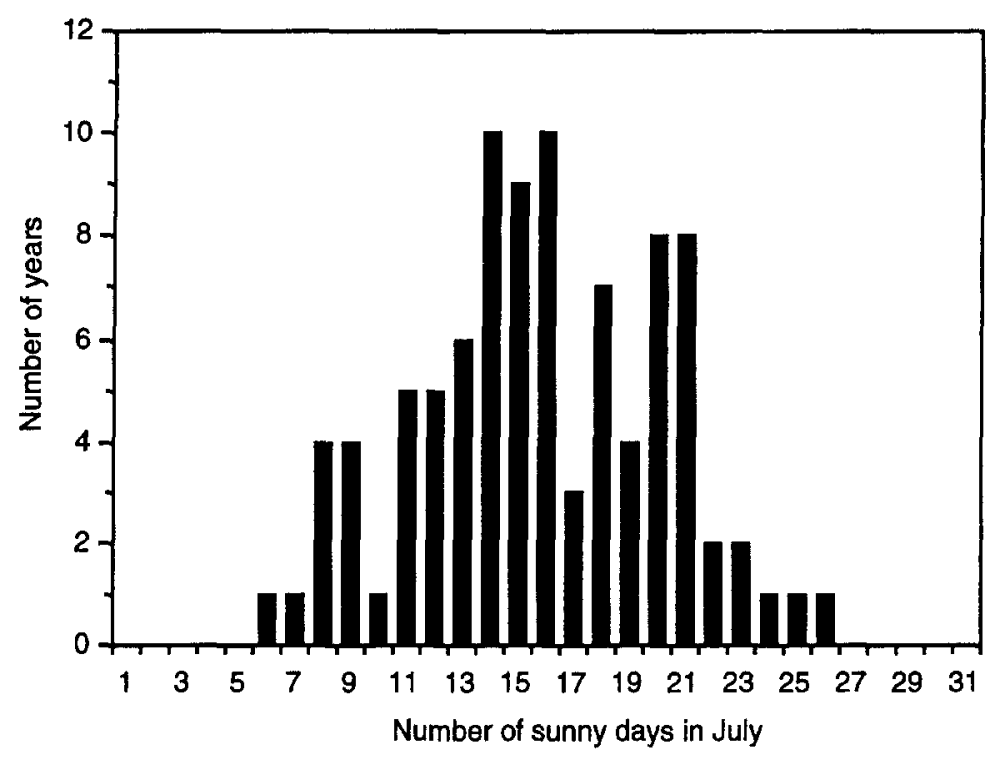

Figure 7. Frequencies of sunny days (with at least $70 \%$ of potential duration) in July in Geneva.

\section{Statistical and Graphical Expressions of Interannual Variability}

These two examples of expectations and frustrations, concerning sunshine in summer and snow at Christmas, emphasize the fact that climatologists should not neglect the task of reminding people of the fundamentally changing nature of climate in the mid-latitudes. This implies that it is necessary to find ways of communicating the concept of variance as a measure of climate variability to the general public.

One approach to the representation of the interannual variability of climatic data throughout the year is by means of a frequency calendar, in some ways comparable to the probability calendar of the Grenoble climatologists (Péguy, 1976; Risser et al., 1984; Charre et al., 1986). The calendar illustrates the frequency at which different thresholds have been exceeded during the measurement period. These values can be used for planning future investments or activities. Unlike the probability calendar, the frequency calendar is presented on the basis of an arithmetic scale and not a Gaussian one, in order to make it simpler to read and interpret by all kinds of public. The term 'frequency' is preferred to 'probability' as it is the exact definition of what is calculated here.

The calendar allows a representation on a single graph of the frequencies of snow or sunshine exceeding different thresholds for each day of the year. The number of threshold classes and their values can be defined for specific requirements. They are represented by isolines on a graph showing the succession of days on the abscissa and the frequencies for which a given condition is fulfilled on the ordinate. 


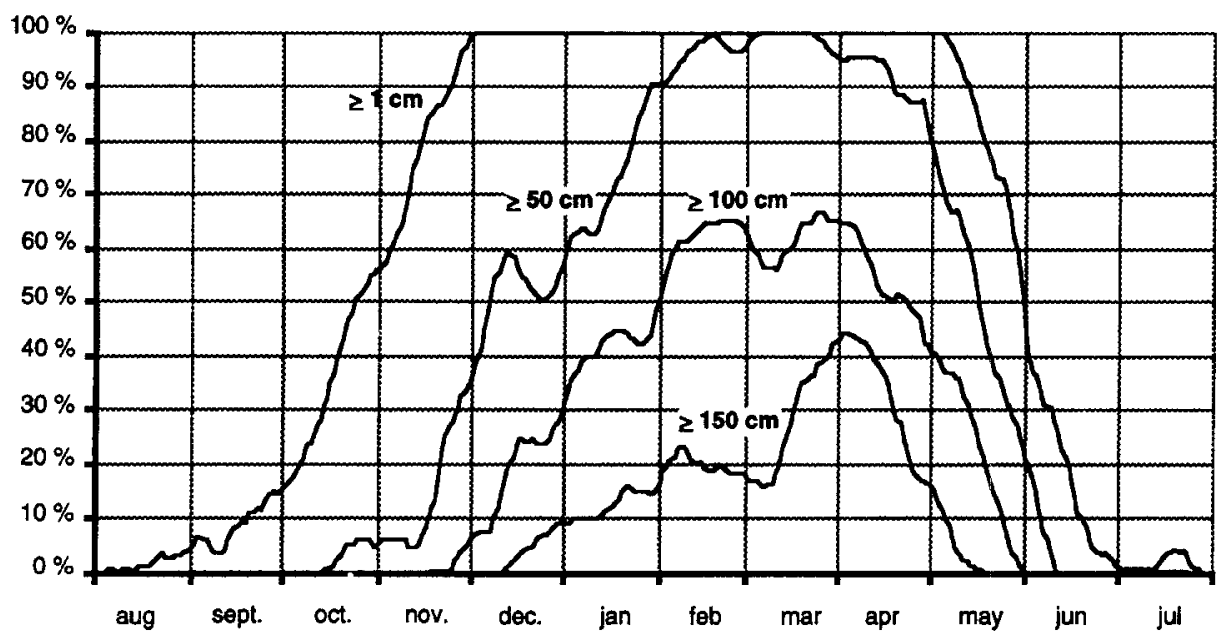

Figure 8. Frequency calendar of snow depth in Grande Dixence (2166 m), 1965-1984.

Figure 8 shows an example of a frequency calendar of snow for an alpine climatological station at an altitude of $2000 \mathrm{~m}$ (Grande Dixence), which corresponds quite well to the altitude of numerous ski slopes in the Alps. It illustrates the necessity of using frequency statistics for this kind of data: for an identical average of $20 \mathrm{~cm}$ of snow on November 15 and on June 1, snow is present four years out of five; only exceptionally (one year out of 20) is there more than $50 \mathrm{~cm}$ on November 15 , whereas on June $1,50 \mathrm{~cm}$ occurs one year out of 5 and no snow at all is observed one year out of two. From another perspective, after May 10, there may already be no snow on the ground at all one year out of 10 , although the average reaches 76 $\mathrm{cm}$, whereas after November 28 , there has always been at least $10 \mathrm{~cm}$, although the average is only $41 \mathrm{~cm}$. In this example, the average snow depth is a variable which has little meaning if it is not associated with the variability around the mean.

This kind of graph is particularly appropriate as a tool to help climatologists communicate information to journalists; scientists often have difficulty in expressing the concept of climate variability. If information provided by a climatologist is more complex than simple arithmetic means, for example, the media will generally request the simplest information and publish it without the words of caution concerning variability. Berk et al. (1995) have shown recently, though, that "we should not underestimate the public's capacity to understand the key scientific issues". Climatological information for the public therefore needs to be clear, complete and well documented, but certainly not oversimplified.

The frequency calendar allows the possibility of compiling a large amount of data and of highlighting the strong variability of mid-latitude climate. With an accompanying explanatory text, it is quite easy to understand and its application to a wide range of situations is relatively straightforward. One advantage is that it provides a measure of risk. It is thus possible to plan a long-term budget taking into 


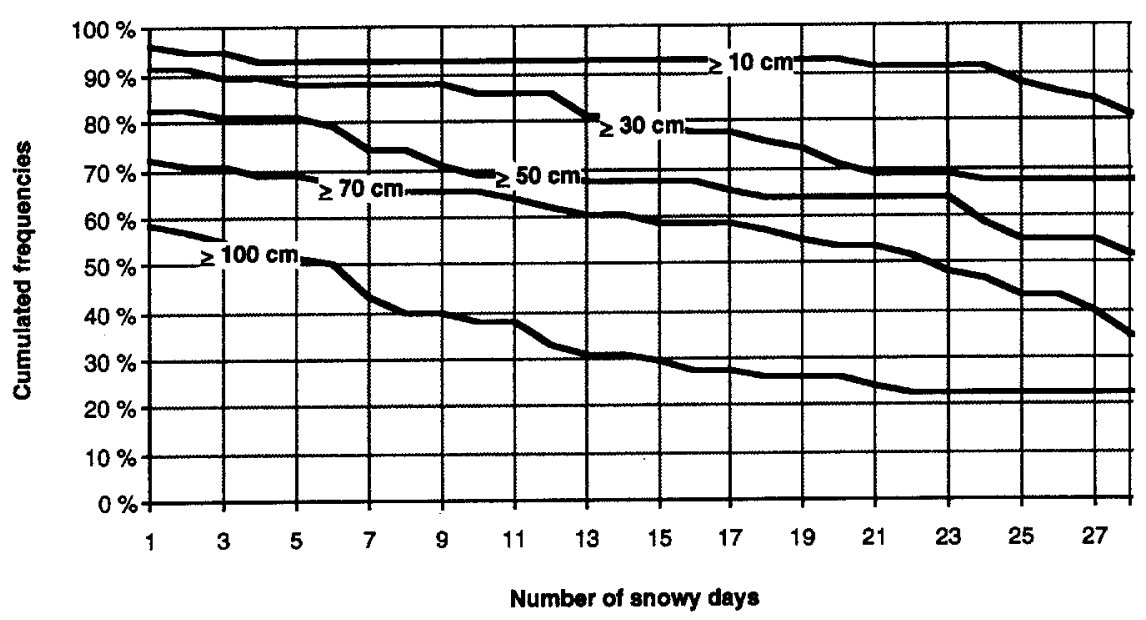

Figure 9. Frequencies of snowy days in February in Montana (1495 m), for 5 different snow-depth thresholds, 1931-1993.

account financial loss through bad weather for a given percentage of years. Another advantage is that this kind of information allows the public to put meteorological and extreme events into a wider perspective; it thus contributes to reduce confusion related to information on global change on the one hand and meteorological events on the other hand (Bostrom et al., 1994). It helps understanding that in the midlatitudes, non-average events are not necessarily abnormal, as the norm implies a wide range of possibilities, nor are they necessarily linked to global climatic change.

A graph of cumulated frequencies is another manner of presenting climatological data when not only a specific date is concerned but also a longer period, such as a month or an entire season. This technique has been frequently used in geology (grain-size distribution curves) but not in climatology. Like the frequency calendar, it allows a presentation of many thresholds on the same graph.

Figures 9 and 10 show examples of graphs of cumulated frequencies for a period of one month and three months, respectively. It groups three snow-depth thresholds at a particular mountain resort. In the resort of Montana, if $30 \mathrm{~cm}$ of snow is the critical depth which allows downhill skiing to take place, and $10 \mathrm{~cm}$ is the appropriate threshold for cross-country skiing, it would be possible to practise downhill skiing during the whole month of February seven years in ten; skiing each day from January to March is statistically possible only one year in five. On the other hand, cross-country skiing would be possible during the whole month of February seven years in ten and every day from January to March two years out of five. This kind of graph can be used as a decision-making tool for infrastructure and equipment in mountain resorts (sports, snow-clearing gear, etc.). It can also help to assess the extent to which the lack of snow which the Alps experienced in the late 80 s and early $90 \mathrm{~s}$ was exceptional. 


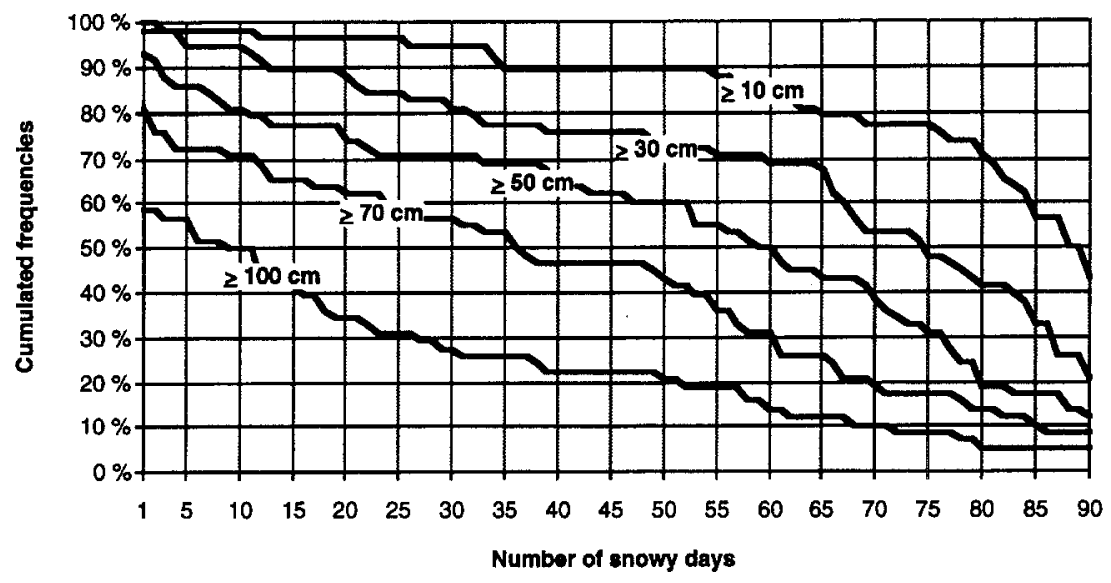

Figure 10. Frequencies of snowy days during the period January-February-March in Montana (1495 m), for 5 different snow-depth thresholds, 1931-1993.

Whatever the graphical technique used, the main point which this section is attempting to convey is that the usual arithmetical averages should be replaced by more meaningful repesentations of climatological data, in particular frequential statistics. In this sense, every means available should be used to provide novel approaches to climatological statistics aimed at the general public.

\section{Conclusions}

Human perception of climate is strongly influenced by expectations, which may have little relationship to the true nature of climate as provided by the instrumental record. Christmas has now become a time when people expect snow. Nevertheless statistics show that below the 700-m level in the Swiss Plateau, where $90 \%$ of the Swiss population lives today, snow on Christmas Day is infrequent, although it can be seen on the nearby mountains. Snow at Christmas time may only be found with close to $100 \%$ certainty at resorts located above $1,500 \mathrm{~m}$. No significant trend concerning the presence of snow on Christmas Day is detected in the instrumental record over the last 60 years.

The context is different regarding the expectation of sunshine in summer. In this case, the expectation is statistically justified in the long term. Causes of disappointment are related to the strong interannual variability of sunshine typical of mid-latitude climate. Although summer is on average the sunniest period of the year, July sunshine duration may on occasion be as low as during winter months.

High variability is a very important characteristic of the alpine climate, both physically and in terms of human perception. Arithmetic averages are an oversimplified manner of conveying to the public information on climate in their region; it is more appropriate to use frequential statistics to allow people to place abnormal 
events into context or to quantify probabilities. Due to the important interannual variability of alpine climate, days with snow or sunshine amount close to long-term average values are much less common than those which differ from the average. Comparing values to arithmetic means is not appropriate as far as human perception of climate is concerned, and indeed often contributes to induce misconceptions on climate issues. Winter days warmer than average can thus easily be interpreted by non-specialists as a sign of global warming, while a period cooler than average may be considered by others as a sign or even proof that the greenhouse effect does not exist. Such preconceived ideas still persist (Bostrom et al., 1994) despite the fact that scientists attempt to explain that global change may be detected only on the long-term and not through isolated events.

If climatologists wish to communicate information about global change efficiently, the public must have the necessary means of evaluating local and shortterm events, to place them in a wider context and on the adequate scale. Only then will a thorough understanding of local and short-term events enable non-specialists to differentiate between these events and global and long-term phenomena, i.e., between 'weather' and 'climate'. To reach this goal, ideas for more appropriate forms of climatological data representation have been suggested here. The frequency calendar and the graph of cumulated frequencies constitute such examples of data representation techniques.

\section{Acknowledgements}

This research has been supported by the Swiss National Science Foundation, grant numbers 10-2064.86 and 4031-038271.

\section{References}

Abegg, B. and Froesch, R.: 1994, 'Climate Change and Winter Tourism: Impact on Transport Companies in the Swiss Canton of Graubünden', in Beniston M. (ed.), Mountain Environments in Changing Climates, Routledge Publishing Company, London and New York, pp. 328-340.

Barry, R. G.: 1995, 'Evidence of Changes in Snow Conditions at High Elevation Sites', Abstract for Workshop on Climatic Change at High Elevation Sites, Wengen, Switzerland, September 11-15, 1995.

Beniston, M., Rebetez, M., Giorgi, F., and Marinucci, R.: 1994, 'An Analysis of Regional Climate Change in Switzerland', Theor. Appl. Climatol. 49, 135-159.

Berk, R. A. and Schulman, D.: 1995, 'Public Perceptions of Global Warming', Climatic Change 29, $1-33$.

Bostrom, A., Morgan, M. G., Fischhoff, B., and Read, D.: 1994, 'What Do People Know about Global Climate Change. 1. Mental Models', Risk Analysis 16 (6), 959-970.

Bradley, R. S. and Jones, P. D.: 1992, Climate since A.D. 1500, Routledge, London.

Cauquelin, A.: 1989, L'Invention du Paysage, Plomb, Paris.

Charre, J., Saintignon, M.-F., Douguedroit, A., and Martin, S.: 1986, 'Modélisation de la Variabilité Climatique', Revue Géographie Alpine 74. 
Farhar-Pilgrim, B.: 1985, 'Social Analysis', in Kates, Robert W. et alii (eds.), Climate Impact Assessment: Studies of the Interaction of Climate and Society, Chichester and New York, pp. 323-350.

Hornung, C. P.: 1970, An Old-Fashioned Christmas in Illustration and Decoration, Dover Publications, New York.

Jacobson, H. and Price, M.: 1990, A Framework for Research on the Human Dimensions of Global Environmental Change, ISSC/UNESCO, Paris.

Jaeger, C. Dürrenberger, G., Kastenholz, H., and Truffer, B.: 1993, 'Determinants of Environmental Action with Regard to Climate Change', Climatic Change 23, 193-211.

Kearney, A. R.: 1994, 'Understanding Global Change: A Cognitive Perspective on Communicating Through Stories', Climatic Change 27, 419-441.

Kempton, W., Boster, J. S., and Hartley, J. A.: 1995, Environmental Values in American Culture, MIT Press, Cambridge and London.

Klineberg, S. L.: 1994, 'The Determinants of Environmental Concern in the American Population, An Interim Report from Two Surveys in Texas', Fall Meeting, American Geophysical Union, published as a Supplement to Eos, p. 52.

Lamb, H. H.: 1982, Climate, History and the Modern World, Methuen, London and New York.

Lamb, H. H.: 1988, Weather, Climate and Human Affairs: A Book of Essays and Other Papers, Routledge, London and New York.

Le Roy Ladurie, Emmanuel: 1983, Histoire du Climat Depuis l'An Mil, Vol. 2, Flammarion.

Office fédéral de la statistique (OFS): 1992, Statistique de la Suisse, Vol. 19, OFS, Berne.

Péguy, C. P.: 1976, 'Une Nouvelle Expression Graphique de la Variabilité Interannuelle des Climats: Les "Calendriers de Probabilites"', Bull. Ass. Géographes Français.

Pfister, Christian: 1988, Klimagescichte der Schweiz: 1525-1860: das Klima der Schweiz von 15251860 und seine Bedeutung in der Geschichte von Bevölkerung und Landwirtschaft, Bern, Stuttgart.

Pielke, R. A. Jr.: 1994, 'Scientific Information and Global Change Policymaking', Climatic Change 28, 315-319.

Read, D., Bostrom, A., Morgan, M. G., Fischhoff, B., and Smuts, T.: 1994, 'What Do People Know about Global Climate Change. 2. Survey Studies of Educated Laypeople', Risk Analysis 14 (6), 971-982.

Rebetez, M.: 1986, Les Saints de Glace, Saint Médard et les Autres. . , Stratus, Oron-la-Ville.

Rebetez, M.: 1994, Perception du Temps et du Climat: Une Analyse du Climat de Suisse Romande sur la Base des Dictions Populaires, Ph.D. Thesis, University of Lausanne, Stratus, Oron-la-Ville.

Risser, Vincent and Martin, Serge: 1984, 'Graphical and Statistical Techniques to Describe SnowCover Variations in Mountain Environments', J. Climatol. 4, 287-296.

Stern, P. C., Young, O. R., and Druckman, D.: 1992, Global Environmental Change: Understanding the Human Dimensions, National Academy Press, Washington DC.

Walter, F.: 1990, Les Suisses et l'Environnement, Zoe, Genève.

Wanner, H. and Pfister, C.: 1994, 'The Late Maunder Minimum (1675-1704) - A Key period for Studying Rapid Climate Change in Europe', in Brazdil R. and Kolar, M. (eds.), Contemporary Climatology, Proc. Meeting Commission on Climatology Int. Geographical Union, Brno.

White, A. V.: 1985, 'Perception', in Kates, Robert W. et alii (eds.), Climate Impact Assessment: Studies of the Interaction of Climate and Society, pp. 403-436.

(Received 20 October 1994; in revised form 1 December 1995) 